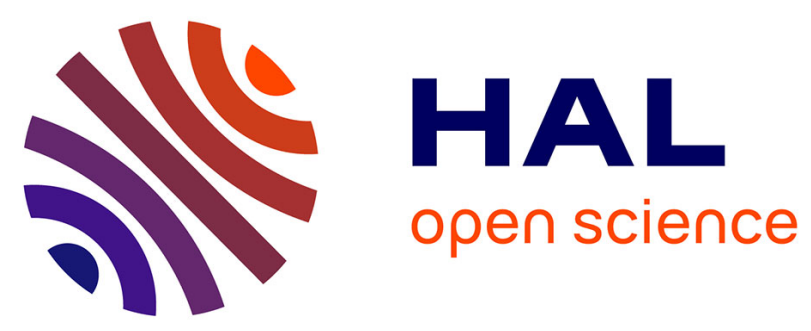

\title{
Evidence of an Early Physical Activity Reduction in Chronic Obstructive Pulmonary Disease Patients
}

Fares Gouzi, Christian Prefaut, Aldjia Abdellaoui, Anne Vuillemin, Nicolas Molinari, Gregory Ninot, Gwenaelle Caris, Maurice Hayot

\section{- To cite this version:}

Fares Gouzi, Christian Prefaut, Aldjia Abdellaoui, Anne Vuillemin, Nicolas Molinari, et al.. Evidence of an Early Physical Activity Reduction in Chronic Obstructive Pulmonary Disease Patients. Archives of Physical Medicine and Rehabilitation, 2011, 92 (10), pp.1611 - 1617.e2. 10.1016/j.apmr.2011.05.012 . hal-01623976

\section{HAL Id: hal-01623976 \\ https://hal.umontpellier.fr/hal-01623976}

Submitted on 25 Oct 2017

HAL is a multi-disciplinary open access archive for the deposit and dissemination of scientific research documents, whether they are published or not. The documents may come from teaching and research institutions in France or abroad, or from public or private research centers.
L'archive ouverte pluridisciplinaire HAL, est destinée au dépôt et à la diffusion de documents scientifiques de niveau recherche, publiés ou non, émanant des établissements d'enseignement et de recherche français ou étrangers, des laboratoires publics ou privés. 


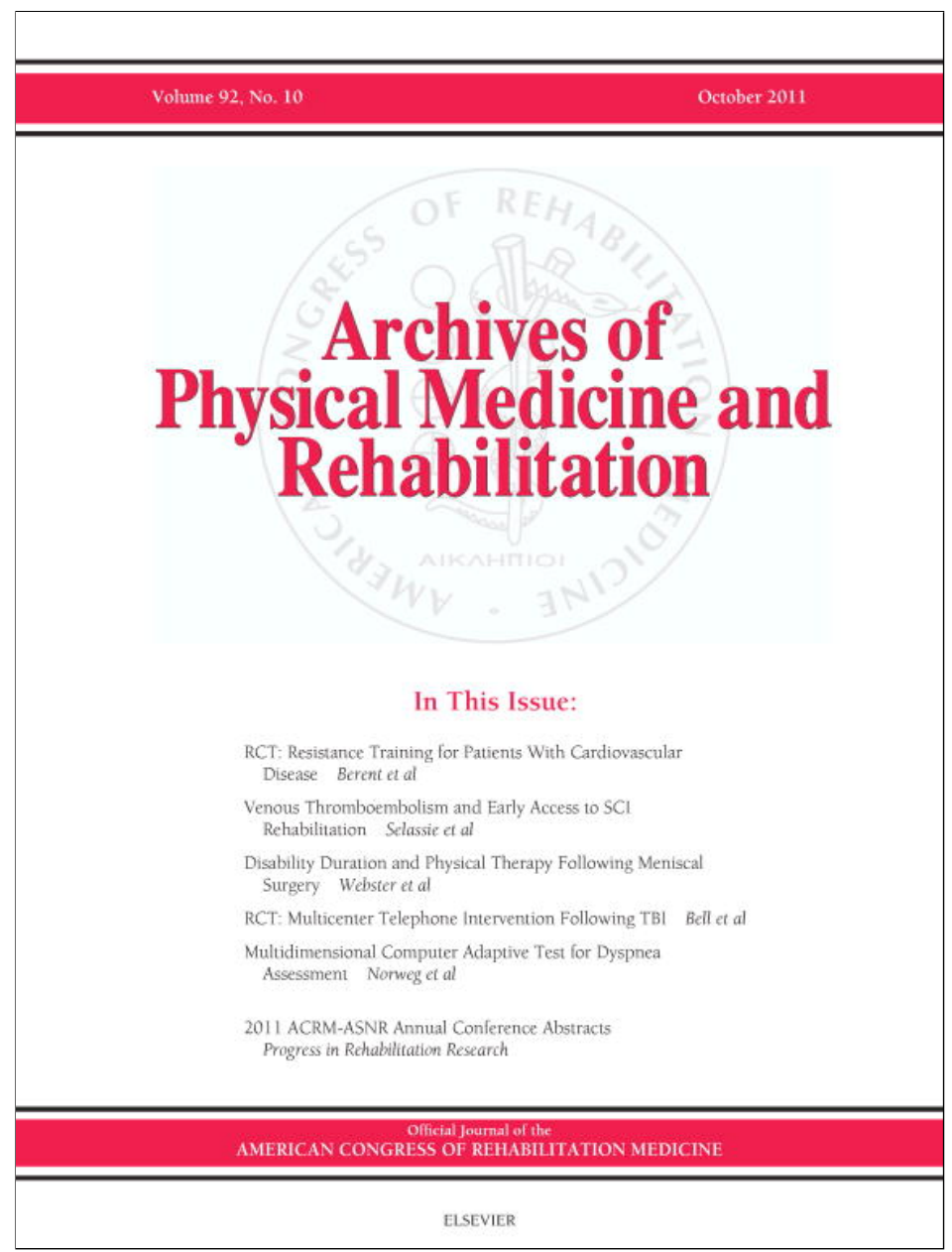

This article appeared in a journal published by Elsevier. The attached copy is furnished to the author for internal non-commercial research and education use, including for instruction at the authors institution and sharing with colleagues.

Other uses, including reproduction and distribution, or selling or licensing copies, or posting to personal, institutional or third party websites are prohibited.

In most cases authors are permitted to post their version of the article (e.g. in Word or Tex form) to their personal website or institutional repository. Authors requiring further information regarding Elsevier's archiving and manuscript policies are encouraged to visit:

http://www.elsevier.com/copyright 


\title{
Evidence of an Early Physical Activity Reduction in Chronic Obstructive Pulmonary Disease Patients
}

\author{
Fares Gouzi, MD, Christian Préfaut, MD, PhD, Aldjia Abdellaoui, PT, MS, Anne Vuillemin, PhD, \\ Nicolas Molinari, PhD, Gregory Ninot, PhD, Gwenaelle Caris, RN, Maurice Hayot, MD, PhD
}

ABSTRACT. Gouzi F, Préfaut C, Abdellaoui A, Vuillemin A, Molinari N, Ninot G, Caris G, Hayot M. Evidence of an early physical activity reduction in patients with chronic obstructive pulmonary disease. Arch Phys Med Rehabil 2011;92: 1611-7.

Objective: To compare the lifetime pattern of physical activity (PA) in chronic obstructive pulmonary disease (COPD) patients and sedentary healthy subjects (SHS) using a PA questionnaire with a lifetime period of recall (Quantification de l'Activité Physique [QUANTAP] system), and to compare the pattern of PA reduction in COPD patients with the onset of breathlessness and other relevant clinical events in this disease (diagnosis, first rehabilitation, onset of smoking).

Design: Cross-sectional comparative study.

Settings: Outpatient university hospital and inpatient pulmonary rehabilitation center.

Participants: COPD patients $(n=129$; mean age \pm SD, $61 \pm 10 \mathrm{y}$; forced expiratory volume in $1 \mathrm{~s}, 57 \pm 23 \%$ ) and SHS $\left(\mathrm{n}=29\right.$; mean age $\pm \mathrm{SD}, 61 \pm 5 \mathrm{y} ;<150 \mathrm{~min} \cdot \mathrm{wk}^{-1}$ of moderatevigorous $\mathrm{PA}$ ).

Interventions: Not applicable.

Main Outcome Measures: Lifetime PA was compared in COPD patients and SHS using the QUANTAP system. The patients with COPD and SHS underwent pulmonary function, exercise, and quadriceps endurance testing. The current PA level was assessed with a triaxial accelerometer and the Voorrips questionnaire. The age at the onset of breathlessness was also recorded.

From the Department of Clinical Physiology, Laboratory INSERM U-1046, CHRU Montpellier, University Montpellier I, Montpellier (Gouzi, Préfaut, Abdellaoui, Hayot); Pulmonary Rehabilitation Center "La Solane," Osséja (Gouzi, Caris), Pulmonary Rehabilitation Center "La Vallonie," Lodève (Abdellaoui); Laboratory EA 4360 Apemac, Universities of Nancy, Metz, and Paris-Descartes, Vandœuvre-lesNancy (Vuillemin); Department of Medical Information, A. De Villeneuve Hospital, Laboratory EA 2415, University of Montpellier I, Montpellier (Molinari); Laboratory Epsylon, EA4556 Dynamics of Human Abilities \& Health Behaviors, University Montpellier I, Montpellier (Ninot), France.

Presented to the European Respiratory Congress, September 12-16, 2009, Vienna, Austria.

Supported by the Centre Hospitalier Regional Universitaire Montpellier and the patient associations, Association pour l'Assistance et la Réhabilitation au Domicile and Association Nationale pour les Traitements A Domicile, les Innovations et la Recherche; a Conventions Industrielles de Formation par la Recherche (CIFRE) gran from the Fontalvie Corporation, Toulouges, France; and the French Ministère délégué à la recherche et aux nouvelles technologies.

A commercial party having a direct financial interest in the results of the research supporting this article has conferred or will confer a financial benefit on the author or one or more of the authors. Gouzi and Abdellaoui were supported by a CIFRE gran from the Fontalvie Corporation, Toulouges, France, and the French Ministère délégué à la recherche et aux nouvelles technologies. Préfaut is the president of the medical committee of Fontalvie Corporation, Toulouges, France, and is an expert consultant to Boehringer Ingelheim, Novartis, Astra-Zeneca, and Vitalair. Vuillemin, Molinari, Ninot, Caris, and Hayot have no conflict of interest to disclose.

Reprint requests to Fares Gouzi, MD, Dept of Clinical Physiology, Laboratory INSERM U-1046, A. de Villeneuve Hospital, University of Montpellier I, Montpellier, France, e-mail: f-gouzi@chu-montpellier.fr.

0003-9993/11/9210-00270\$36.00/0

doi:10.1016/j.apmr.2011.05.012
Results: Accelerometry showed no significant difference between patients and SHS (in vector magnitude units, $136 \pm 56$ vs $135 \pm 47 ; P=.95$ ). Within the past 15 years, the cumulated PA level was not different for each 5 -year period. Then, from the period of 16 to 40 years ago, it was systematically higher in patients compared with SHS (in metabolic equivalent/y ${ }^{-1}$, median [interquartile range], 6973 [5400-12,207] vs 4248 [3545-5919]; $P<.05)$. The COPD patients reduced their PA earlier than the SHS (45y vs 55y; $P<.01$ ), and the PA was dropped before the onset of breathlessness (45y vs $49 \mathrm{y}$; $P<.001)$

Conclusions: The observation of an early PA reduction, preceding the onset of breathlessness, suggests the implication of prior pathologic mechanisms in the PA reduction of COPD patients.

Key Words: Dyspnea; Muscle; Skeletal; Rehabilitation; Sedentary lifestyle; Tobacco.

(C) 2011 by the American Congress of Rehabilitation Medicine

$\mathbf{T}$ HE SKELETAL MUSCLE dysfunction of chronic obstructive pulmonary disease (COPD) patients ${ }^{1}$ is associated with several cellular alterations (fiber atrophy, type I fiber loss, metabolic changes ${ }^{2}$ ) and has been imputed to a sedentary lifestyle. ${ }^{1}$ However, indirect comparisons indicate that these muscle alterations are more severe in COPD patients than in sedentary healthy subjects (SHS). ${ }^{2}$ The explanations may lie with the differences in the patterns of sedentariness in the 2 populations. First, current physical activity (PA) level (planned and structured regular exercise performed deliberately) and daily living activities (eg, workplace and household PA) in COPD are lower than those in the SHS control groups., Second, a longer duration of inactivity ${ }^{5}$ in COPD causes greater alterations due to the dose-response effect of PA. ${ }^{6}$ Indeed, the PA reduction may be triggered earlier by the onset of breathlessness, as suggested by the COPD spiral-of-decline model. ${ }^{7,8}$ Unfortunately, PA has only been investigated over

List of Abbreviations

$\begin{array}{ll}\text { COPD } & \text { chronic obstructive pulmonary disease } \\ \text { CS } & \text { control subjects } \\ \text { FEV } & \text { forced expiratory volume in 1 second } \\ \text { FVC } & \text { forced vital capacity } \\ \text { IQR } & \text { interquartile range } \\ \mathrm{MET} & \text { metabolic equivalent } \\ \mathrm{PA} & \text { physical activity } \\ \mathrm{PaO}_{2} & \text { arterial partial pressure of oxygen } \\ \mathrm{QUANTAP} & \text { Quantification de I'Activité Physique } \\ \mathrm{SEM} & \text { standard error of the mean } \\ \mathrm{SHS} & \text { sedentary healthy subjects } \\ \mathrm{T}_{\mathrm{Iim}} & \text { quadriceps endurance time } \\ \mathrm{VO}_{2 \mathrm{sl}} & \text { symptom-limited oxygen consumption }\end{array}$


relatively short periods, ${ }^{3,9}$ and the hypothesis of major and prolonged exposure to sedentariness remains to be proved.

A longitudinal study to assess the lifetime PA pattern of COPD patients would require repeated measurements of PA over decades in a single cohort. A more practical alternative is to use a PA questionnaire with a lifetime period of recall, as the reliability of distant-past PA recall has been well demonstrated. ${ }^{10}$ We thus chose to use the Quantification de l'Activité Physique (QUANTAP) system, which has been validated for the assessment of the time course of lifetime PA in the general population $^{11}$ and has been used to determine the effects of lifetime PA on chronic disease. ${ }^{12}$ We expected that this tool would provide a valuable description of the natural history of PA in COPD, as well as preliminary evidence regarding how well the spiral-of-decline model fits the COPD process.

The first aim of this study was thus to compare the lifetime pattern of PA in COPD patients and SHS using the QUANTAP system. The secondary aim was to compare the age of PA reduction in COPD patients with the age at the onset of breathlessness and the age of other clinical events (diagnosis, first rehabilitation, onset of smoking).

\section{METHODS}

\section{Participants}

COPD patients referred for follow-up or a pulmonary rehabilitation program were screened from May 2008 to October 2010 on the basis of the following criteria: association of cough, sputum, or dyspnea and spirometry (forced expiratory volume in 1 second/forced vital capacity, $\left[\mathrm{FEV}_{1} / \mathrm{FVC}\right]<70 \%$, not fully reversible airway obstruction). ${ }^{13}$ Exclusion criteria included other respiratory diagnoses, major comorbidity, memory impairment, exacerbation in the last 2 months, and participation in a pulmonary rehabilitation program more than 5 years before the study (which may have durably changed the lifetime PA pattern). Rehabilitation within the past 5 years was not an exclusion criterion because previous studies suggested that pulmonary rehabilitation would not change the lifetime pattern of PA. ${ }^{14-16}$ Additional information can be found in the multimedia files, supplementary material, section subjects, and methods. After clinical examination and a complete interview, all patients performed the tests in our laboratory and in the pulmonary rehabilitation center. Disease status was assessed using the spirometric value of the postbronchodilatator $\mathrm{FEV}_{1}$, according to the former staging system of the Global Initiative for Obstructive Lung Disease. ${ }^{13}$

During this time, SHS of the same age were recruited via a local newspaper on the basis of the following criteria: aged from 50 to 75 years, no disease, and less than 150 minutes of moderate to vigorous PA per week (corresponding to the recommended threshold for health improvement). ${ }^{17,18}$ Active or exsmokers $(>10$ pack/y or stopped within the past $5 y)$ were excluded from the study.

Informed written consent was obtained from all subjects, and the research protocol was approved by the institutional ethics committee of the university hospital ( $\left.n^{\circ} 2009-04-B P C O-V 2\right)$ and conducted in accordance with the Helsinki Declaration and the European Guidelines for Good Clinical Practice.

\section{Physical Activity}

Voorrips questionnaire (modified Baecke's questionnaire) and actimetry. In order to assess the PA level of our sedentary-selected healthy population, we used a PA questionnaire validated $^{19}$ and used in this indication. ${ }^{1}$ With this method, healthy subjects with scores under 9.4 are classified as having low PA. The objective PA level was assessed in 20 COPD patients and 20 SHS who wore a triaxial accelerometer ${ }^{\mathrm{a}}$ validated in COPD 20,21 for 7 consecutive days (see in multimedia file, supplementary material, section subjects, and methods).

QUANTAP system. The QUANTAP interview-administered survey is a computer-assisted tool designed to determine PA over a lifetime in 4 dimensions (sports at school, leisure sports, occupation, daily activities). Briefly, the data for PA were collected from birth up to the present (at the time of the study). The information recorded for each type of activity included the number of years it had been performed, the number of months per year, the number of sessions per month, and the average duration of each session. In order to improve the accuracy of recall, the date of each PA was linked to a meaningful event in the subject's life. Indicators of energy expenditure were calculated by the software for each of the dimensions and expressed in metabolic equivalents (METs) per year, on the basis of the classical compendium. The PA in MET. ${ }^{-1}$ for 20 - or 5 -year periods from the date of birth going forward or from the date of the study backward, as well as lifetime PA, was then derived for use in the subsequent analysis. The age when PA dropped was individually assessed by 2 blinded observers. The rate of decrease was calculated for each time period as the ratio of the PA level minus the PA level (during the last 5-year period) divided by the time. This questionnaire is reliable to assess lifetime PA and has been validated for use in elderly subjects ${ }^{11}$ and in the context of various pathologies. $^{12}$

Given the lack of published data, we specifically verified 3 key methodologic points in our COPD patients:

1. The intraobserver reproducibility of the QUANTAP questionnaire. COPD patients responded to the questionnaire twice, with a 1 -week interval. No significant differences in responses were observed $(P=.11)$. The intraobserver correlation coefficient was $\operatorname{good}\left(R^{2}=.92\right.$; $\mathrm{n}=17$ ).

2. The accuracy of long-term PA recall. The agreement between recalled PA level and the original reports made

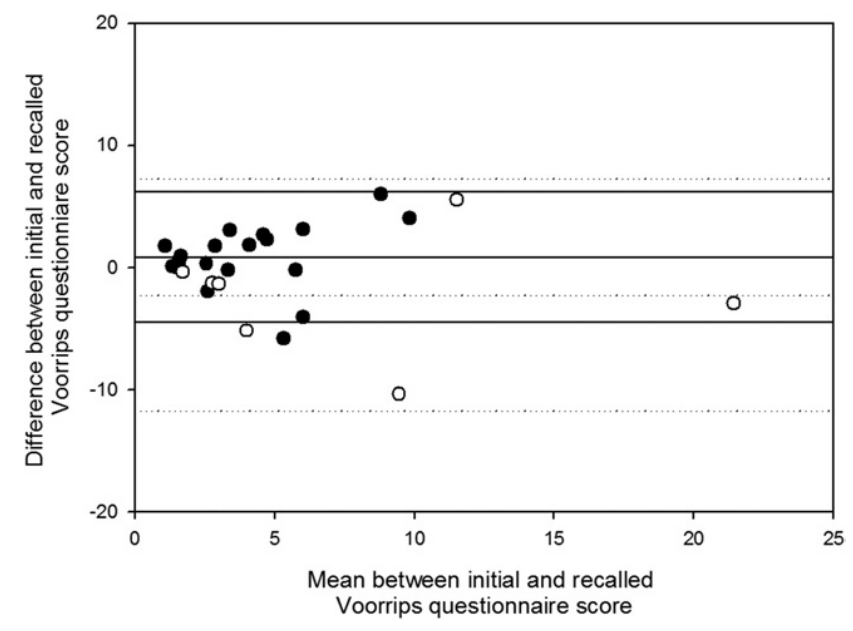

Fig 1. Agreement between the recalled PA level in 2000 (Voorrips questionnaire score) and the original Voorrips questionnaire score recorded in 2000, in COPD patients (black circles) and SHS (white circles)..$^{45}$ Bland and Altman ${ }^{22}$ graphic method. Individual differences are plotted against their respective means. The central line ences are plotted against their respective means. The central line
corresponds to the mean of the difference, and the upper and lower control lines delimit the $95 \%$ confidence interval (COPD patients, solid lines; SHS, dotted lines). 
10 years before were assessed with the Voorrips questionnaire in 19 COPD patients and 7 SHS. A Bland and Altman $^{22}$ analysis showed neither under- nor overestimation in COPD patients (fig 1). The agreement remained acceptable for the range of Voorrips questionnaire scores in our COPD patients, although it was less satisfying for higher scores. Last, all patients were within the $95 \%$ confidence interval of the difference determined for the SHS, indicating that the long-term PA recall of the COPD patients was not less accurate than that of the SHS.

3. The potential memory bias for the distant past.

We compared the lifetime PA of the 129 COPD patients with that of 50 active control subjects. This homogenous group was composed of active healthy subjects who had been recruited at the same time and place as the SHS and was completed by subjects corresponding to the published data of Vuillemin et al. ${ }^{12}$ These control subjects were not sedentary (none had a total PA level under 540MET.wk ${ }^{-1}$ in the past 5y, which corresponds to $150 \mathrm{~min} / \mathrm{wk}^{-1}$ of brisk walking), but all were untrained (all had spent less than 2688MET.wk ${ }^{-1}$ practicing sports in the past $5 \mathrm{y}$, which corresponds to $1 \mathrm{~h}$ daily of endurance training, like cycling). More than 20 years ago-that is, before disease onset when they were probably still healthythe PA level of the COPD patients was equal to that of the control subjects: there was no significant difference between PA levels for the period of 40 to 20 years ago (median [interquartile range, IQR], 6702 [4251-10,278] and 6973 [5400$12,207]$ MET. $^{-1}$, respectively; $P=.27$ ), and for the period of 60 to 40 years ago (median [IQR], 3247 [1334-5585] and 2734 [1182-3832] MET.y ${ }^{-1}$, respectively; $P=.39$ ), indicating no misestimation of recalled PA more than 20 years ago (supplemental fig 1).

\section{Age at Dyspnea Onset/Age at Diagnosis}

Breathlessness was systematically recorded using the patient's own dyspnea vocabulary. The severity via the Medical Research Council scale ${ }^{23}$ and the age at first occurrence were documented. In order to improve the precision of the patient's recall of the first experience of breathlessness, questions were asked by an experienced practitioner after the lifetime PA interview and exercise tests, and the intraobserver consistency was assessed in a preliminary analysis (see supplementary material, section subjects and methods). All clinical events in the disease (diagnosis, first rehabilitation, onset of smoking) were linked to meaningful events in the subject's life (children's birthdays, wedding anniversary, work, etc).

\section{Pulmonary Function Tests and Arterial Blood Gases}

All subjects underwent whole body plethysmography (Transmural Bodybox $2800^{\mathrm{b}}$ ) according to the American Thoracic Society/European Respiratory Society Task Force standardization of lung function testing. $\mathrm{FEV}_{1}$ and $\mathrm{FVC}$ were measured and the $\mathrm{FEV}_{1} / \mathrm{FVC}$ ratio was calculated. The values were compared with normative values. ${ }^{24}$ Arterial blood samples were obtained from the radial artery of seated COPD patients while they breathed room air. Partial pressure of oxygen in the alveoli $\left(\mathrm{PaO}_{2}\right)$ was measured with a blood gas analyzer ${ }^{\mathrm{c}}$ using the Clarck electrode method. As recommended, a 3-level control quality was done after every electrode or solution change and every 2 automatic 2-point calibration. This 2-point calibration was done using ambient air and a determination solution of the zero, every 24 hours. As some of the samples were collected at an altitude of $1250 \mathrm{~m}$, the $\mathrm{PaO}_{2}$ and oxygen saturation as measured by pulse oximetry values were corrected for the sea-level barometric pressure.

\section{Exercise Testing and Muscle Function Assessment}

The six-minute walking test was performed in a $30-\mathrm{m}$ corridor as previously described ${ }^{25}$ (see in multimedia files, supplementary material, section subjects, and methods). The distance walked during the test (six-minute walking distance) was compared with reference values. ${ }^{26}$ Participants performed an incremental cycle ergometric test until exhaustion on an electrically-braked cycle ergometer ${ }^{\mathrm{d}}$ to determine maximal power output and symptom-limited oxygen consumption $\left(\mathrm{Vo}_{2 \mathrm{sl}}\right){ }^{27}$ They followed the individualized protocol usually used in our laboratory (3min of workload at $20 \%$ of the max power output followed by $10 \%$ of the max power output/min increment and a 3 min active recovery). ${ }^{7}$ During the exercise test, heart rate, electrocardiograph, blood pressure, and transcutaneous oxygen saturation were monitored. Oxygen consumption and carbon dioxide production were measured and calculated from a breath-by-breath analyzer (Vmax 229 Autobox $^{b}$ ). Maximal power output was the maximal workload sustainable, and symptom-limited $\left(\mathrm{VO}_{2 \mathrm{sl}}\right)$ was the mean value during the last 20 seconds of the test.

The maximal voluntary contraction and endurance time (T.lim) were assessed with the usual methodology ${ }^{1,28}$ (see in multimedia files, supplementary material, section subjects, and methods).

\section{Statistical Analysis}

All continuous variables were tested for normality. They are expressed in mean \pm SD if normally distributed, and in median \pm interquartile range (IQR 25\%-75\%) or \pm standard error of the mean (SEM) if not. Comparisons between COPD patients and SHS were assessed via $t$ tests (normally distributed variables) or the Mann-Whitney $U$ test (nonnormal distribution). Comparisons between patient severity groups included analysis of variance on ranks and least significant difference post hoc analysis.

Kaplan-Meier curves were drawn for the COPD patients to compare the age at PA reduction and the occurrence of clinical events. Differences were tested via the log-rank test. Our sample size provided more than $95 \%$ power to detect any difference of PA 20 years ago $(\alpha=.05)$ between COPD patients and SHS.

\section{RESULTS}

\section{Subjects}

After screening and clinical examination of 186 COPD patients, 129 were found to be eligible (16 eliminated for cognitive impairment or lack of internal consistency, 5 for major heart disease, and 36 for pulmonary rehabilitation more than 5 years ago). One hundred and thirty-six "sedentary" subjects contacted us about the study. After clinical examination and an interview using the Voorrips questionnaire, 40 were found to be healthy and spent less than 150 minutes per week performing moderate to vigorous PA. The week of accelerometric recording and functional assessment determined that 29 of these SHS spent less than 150 minutes per week participating in moderate to vigorous PA and were retained in the analysis. The basic characteristics, including exercise capacity and peripheral muscle function of the COPD patients and the SHS, are presented in table 1.

The prevalence of smoking exposure was very high in the COPD patients (92\% were active or exsmokers). Only 1 SHS was an exsmoker $(<10$ pack-years). The Voorrips questionnaire score was not significantly $(P=.10)$ higher in the COPD patients (5.9 [2.2-9.4] vs 4.1 [3.2-5.6]) compared with SHS, 
Table 1: Characteristics of COPD Patients and SHS

\begin{tabular}{|c|c|c|c|}
\hline Characteristics & COPD & SHS & $P$ \\
\hline $\mathrm{n}$ & 129 & 29 & \\
\hline Age (y) & $61.3 \pm 9.6$ & $61.4 \pm 5.4$ & .810 \\
\hline Sex ratio $(\mathrm{W} / \mathrm{M})$ & $44 / 85$ & $16 / 13$ & 1.000 \\
\hline Professional activity/retired & $47 / 82$ & $12 / 17$ & 1.000 \\
\hline $\mathrm{FEV}_{1}(\%$ pred $)$ & $56.6 \pm 22.8$ & $106.2 \pm 12.9$ & $<.001$ \\
\hline $\mathrm{Hb}(\mathrm{g} / \mathrm{dL})$ & $15.1 \pm 1.6$ & $\mathrm{~N} / \mathrm{A}$ & N/A \\
\hline $\mathrm{SpO}_{2}(\%)$ & $94.5 \pm 3.1$ & $\mathrm{~N} / \mathrm{A}$ & N/A \\
\hline $\mathrm{PaO}_{2}(\mathrm{mmHg})$ & $71.7 \pm 11.5$ & N/A & N/A \\
\hline Tobacco smoke (pack.y) & $46.5 \pm 26.3$ & $1.2 \pm 6.6$ & $<.001$ \\
\hline Dyspnea (MRC) & $3.1 \pm 0.4$ & N/A & N/A \\
\hline BMI $\left(\mathrm{kg} / \mathrm{m}^{-2}\right)$ & $24.7 \pm 4.4$ & $25.7 \pm 2.8$ & .130 \\
\hline \multicolumn{4}{|l|}{ Six-minute walking } \\
\hline distance $(\mathrm{m})$ & $493 \pm 99$ & $607 \pm 64$ & $<.001$ \\
\hline $\mathrm{VO}_{2 \mathrm{SL}}(\%$ pred $)$ & $65.9 \pm 19.6$ & $108.3 \pm 14.3$ & $<.001$ \\
\hline Quadriceps T.lim (s) & $273 \pm 218$ & $475 \pm 341$ & $<.010$ \\
\hline
\end{tabular}

NOTE. Results are expressed in mean \pm SD or as otherwise noted. Abbreviations: \% pred, \% of the predicated value; $\mathrm{M}$, men; MRC, Medical Research Council; BMI, body mass index; $\mathrm{SpO}_{2}$, oxygen saturation as measured by pulse oximetry; $\mathrm{VO}_{2 \mathrm{SL}}$, symptom limited oxygen consumption; W, women.

and accelerometry recording of current PA levels showed no significant difference between patients and SHS (in vector magnitude units, $136 \pm 56$ vs $135 \pm 47 ; P=.95$ ).

\section{Time Course of PA in COPD Patients}

A detailed analysis of the past 40 years was made for the COPD patients and SHS using 5-year steps (fig 2). Within the past 15 years, the cumulated PA level was not different for each 5-year period, then, from the period of 16 to 40 years ago, it was systematically higher in the COPD patients compared with SHS $(P<.05)$.

Therefore, we found a faster decrease in PA 25 years before the study in COPD patients compared with SHS (624 [1191316] vs 388 [30-567] MET.y $\left.{ }^{-1} ; P<.05\right]$ ), but no difference in the rate of decrease was noted for more recent time periods. COPD patients and SHS thus had the same pattern of PA for the past 15 years (amount and rate of decrease). There were no

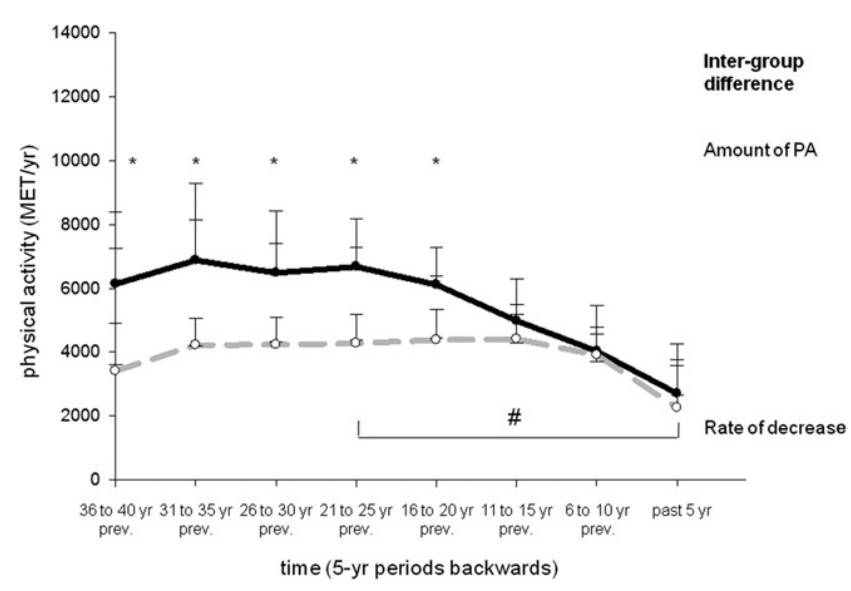

Fig 2. Time course of PA from the date of the study for each 5-year period of time in MET/y ${ }^{-1}$ for COPD patients (black) and SHS (light gray). ${ }^{45}$ Results are expressed in median \pm SEM. Differences between groups at each period were tested for amount of PA. * $P<.05$. Differences between groups at each period were tested for rate of decrease (from past period until now). ${ }^{\#} P<.05$.

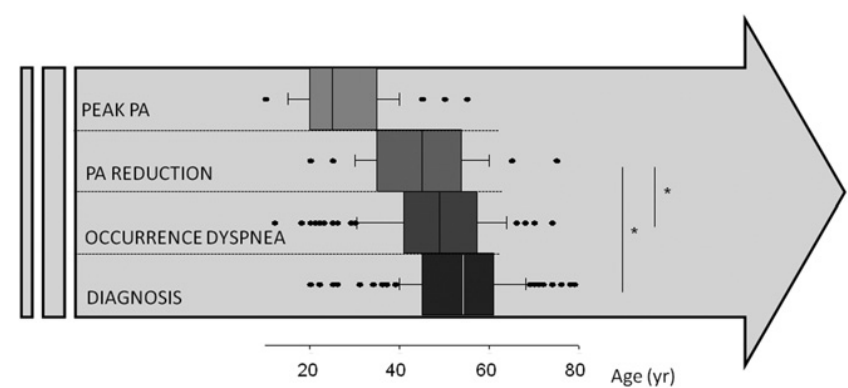

Fig 3. Age at occurrence of PA peak, PA reduction, breathlessness, and diagnosis for COPD patients (y). Box plot showing median; top and bottom edges of the box indicate 75th and 25th percentiles, respectively. The brackets above and below the boxes indicate the 90 th and 10th percentiles, respectively. The additional symbols are values that fall outside the 10 th to 90 th percentile range. ${ }^{*} P<.001$.

significant differences between severity groups (Global Initiative for Obstructive Lung Disease stage; $P=.73$ ). The lifetime PA did not differ between recently rehabilitated and never rehabilitated patients $(65,089$ [47,617-96,429] vs 58,390 $[41,415-78,598]$ MET; $P=.10])$.

\section{Sequence of Clinical Events}

In a forward analysis (ie, from birth), the median age at PA reduction was 45 (35-54) years for the COPD patients and 55 (45-60) years for the SHS $(P<.01)$. The age at PA reduction was correlated with age, but not with sex, marital status, body mass index, disease status, exercise capacity, or peripheral muscle function.

PA was reduced before the onset of dyspnea, which first occurred at a median age of 49 years $(P<.001)$ (fig 3$)$. This reduction also preceded diagnosis $(54 \mathrm{y} ; P<.001)$, retirement $(60 \mathrm{y} ; P<.001)$, and the first pulmonary rehabilitation $(58 \mathrm{y}$; $P<.001)$. The patients started smoking at 17 years $(14-20)$, thus before reducing their PA, and stopped after the PA reduction $(56 \mathrm{y} ; P<.001)$.

At the age of dyspnea onset, $64 \%$ of the patients had already reduced their PA level. Kaplan-Meier analysis confirmed that since birth, the proportion of patients who had reduced their PA was systematically significantly higher than the proportion of dyspneic or diagnosed COPD patients $(P=.01)$ (fig 4$)$.

\section{DISCUSSION}

The present study showed a different lifetime pattern of PA in COPD patients and well-characterized SHS with the same current PA level. First, for the past 15 years, the PA level of the COPD patients was the same as the SHS. Then, from 16 to 40 years ago, before the disease onset, their PA level was higher than the chronic disease-free sedentary subjects. Interestingly, the PA reduction occurred earlier in the COPD patients (at 45-y old) and before any clinical signs of the disease.

\section{Lifetime PA of SHS}

We found the same current PA level in SHS and COPD patients and a lower PA level in SHS compared with the COPD patients more than 15 years ago. First, our SHS were certainly sedentary at the time of inclusion: we selected the subjects on the basis of the international recommendations for a PA level that promotes or maintains health in older adults. ${ }^{17}$ Their current time spent in moderate PA (via accelerometry) was nearly half that reported in another study including control subjects and using the same device and cut-off. ${ }^{29}$ In addition, 


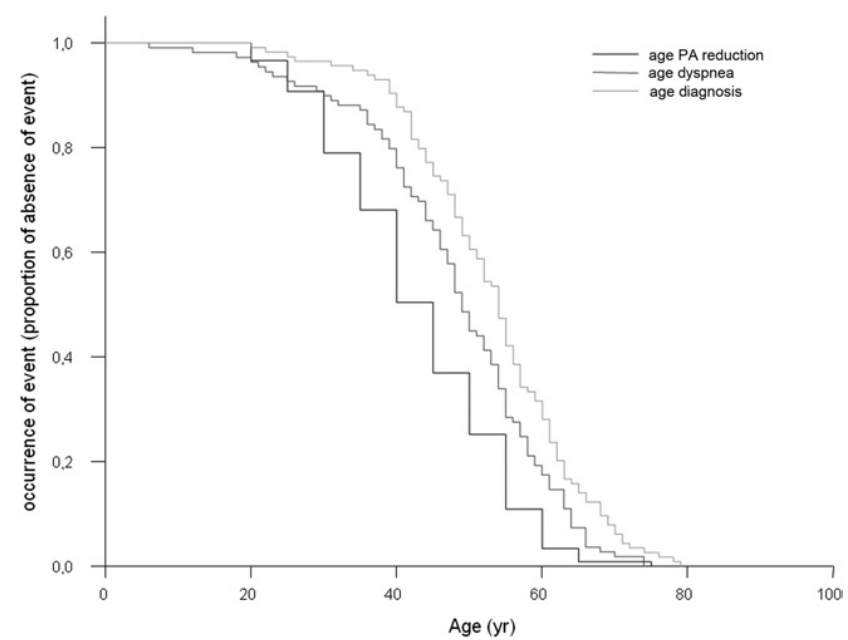

Fig 4. Kaplan-Meier curves for the age at occurrence of PA reduction (black), age at occurrence of breathlessness (gray), and age at diagnosis (light gray). Log-rank $=34.6$ degrees of freedom $=3$. Age at occurrence of PA reduction versus age at occurrence of breathlessness: $P<.001$. Age of $P A$ reduction versus age at diagnosis: $P<.01$.

their Voorrips questionnaire score was also under the threshold of 9.4 , defining low PA.

Second, our results indicate that the SHS had always been sedentary: we observed that compared with the active control subjects. Our SHS reported a significantly lower PA level throughout their lives (see supplemental fig 1). The few longitudinal studies that have prospectively recorded the lifelong PA of healthy subjects support this observation of life-long sedentariness. Indeed, 1 study showed a low but significant correlation between baseline and endpoint PA. ${ }^{30}$ In this cohort, more than half the subjects had maintained the same PA level for 30 years. Two other longitudinal studies showed that the most sedentary subjects at inclusion had the worst $\mathrm{VO}_{2 \mathrm{sl}}$ and the lowest physical functioning 8 and 9 years later. ${ }^{31,32}$ Although no direct comparisons of $\mathrm{VO}_{2 \mathrm{sl}}$ can be made with the latter study, the PA time courses of our SHS and control subjects were consistent with these observations.

\section{Lifetime PA of COPD Patients}

We observed that the COPD patients had a higher PA level than SHS in time periods more than 15 years ago. The observed difference (power of the test $=98 \%$ ) of 1574 MET. ${ }^{-1} 15$ years ago is clinically meaningful, as $540 \mathrm{MET}^{-1} \mathrm{y}^{-1}\left(150 \mathrm{~min} / \mathrm{wk}^{-1}\right.$ of brisk walking) improves health in older subjects. ${ }^{17}$ However, as the selected SHS had no life-altering chronic disease impacting their activity level (as the COPD subjects did), it is not surprising that the COPD subjects had a higher activity level in the past whereas the SHS did not.

This higher PA level contrasts with the current lower exercise capacity and impaired pulmonary function of the COPD patients and is consistent with recent studies that showed discrepancies between PA level and $\mathrm{FEV}_{1} .{ }^{9}$ Moreover, the $40 \%$ lower quadriceps endurance in the COPD patients at the same current and higher past PA level is in line with previous observations. ${ }^{33}$ The modest correlation between PA level or functional performance and quadriceps weakness ${ }^{15}$ can be explained by numerous other factors that have been imputed in the peripheral muscle alterations, such as corticosteroids, systemic inflammation, hypoxemia, and oxidative stress. ${ }^{2}$

For the current PA level, there was no significant difference between COPD patients and SHS, in contrast with other studies that have systematically reported that COPD patients have lower PA than the control groups. However, these control groups had a questionable definition of the PA level: the subjects were retired, ${ }^{3}$ but possibly less inactive than assumed, or were presumed to represent sedentary populations (like chronic bronchitis $^{9}$ ) despite the lack of comparison of their PA level with that of active healthy controls. In our study, we were particularly careful to assess the PA level with several methods. Thus, our results provide complementary detail regarding the data published to date.

\section{Natural History of Physical Activity}

Our COPD patients $(61.3 \pm 9.6 y)$ had normal PA levels more than 20 years ago, and then had a significant PA reduction at a median age of 45 years. This drop in PA occurred 10 years earlier than the PA reduction in SHS. The age at which SHS reduced PA was quite similar to the findings of published national surveys in healthy subjects: PA drops after 60 years in France $^{18}$ at retirement. ${ }^{34}$ Therefore, in COPD, the PA reduction occurred abnormally early.

PA change is complex and usually multifactorial, with age, sex, body mass index, and socioeconomic and psychologic status among the influences. ${ }^{4,35,36}$ However, the proportions of these factors were the same in patients and SHS at the time of assessment. Retirement was as prevalent $(63 \%$ and $59 \%$, respectively; $P=1.00$ ) and occurred at the same age (median, $60 \mathrm{y} ; P=.46$ ) in both groups. We thus found no obvious differences between COPD patients and SHS for the usual determinants of PA changes, except respiratory disease, which has been associated with PA reduction in cross-sectional studies. ${ }^{3}$ The PA reduction could be explained by an early exercise capacity reduction in COPD (like an increase of the ventilator demand, reduction of the arterial oxygen content, ${ }^{37}$ peripheral muscle dysfunction), as observed in stage I of the Global Initiative for Obstructive Lung Disease COPD patients. ${ }^{38}$

However, PA was reduced before diagnosis and the onset of breathlessness, suggesting that these patients had reduced PA before disease onset. These results are in line with the observation of quadriceps dysfunction ${ }^{39}$ and PA reduction ${ }^{9}$ at early stages of the disease. In healthy subjects, many epidemiologic studies have indicated a link between cigarette smoking and sedentariness ${ }^{18}$ and a growing body of evidence argues for the direct toxicity of cigarette smoke on peripheral muscle in non-COPD subjects. ${ }^{4,41} \mathrm{We}$ can thus speculate that cigarette smoking had a deleterious effect on PA, before the onset of the disease. However, this hypothesis requires a specific study designed to compare the PA level of healthy smokers and nonsmokers matched for the main factors influencing the PA level (eg, the previously cited studies assessing the impact of tobacco smoke on the peripheral muscle function). This observation of an early PA reduction is highly relevant for the prevention of COPD. Indeed, according to previous work demonstrating the prognostic value of PA levels, ${ }^{4}$ this new finding supports the potential effectiveness of early exercise training, especially for at-risk populations (ie, smokers), and should be more fully integrated into public health care policies and for the timing of pulmonary rehabilitation. ${ }^{42}$

\section{Study Limitations}

Cognitive dysfunction can introduce variability in and impair the accuracy of PA reports. Therefore, patients with major cognitive dysfunction, which was identified during careful clinical examination and an interview, were not included in the analysis. As cognitive function is only mildly impaired in COPD patients without hypoxemia, ${ }^{43}$ our current patients were 
unlikely to exhibit this problem. Also, the test-retest reproducibility of the QUANTAP questionnaire was acceptable in the COPD patients.

The good accuracy of the recall of PA performed in the distant past has been demonstrated in healthy subjects. ${ }^{44}$ In 1996, Falkner et al ${ }^{10}$ compared the recalled PA of 137 patients of the Buffalo cohort to their original reports in 1960 and found no significant differences. For our study, we used a questionnaire validated in the patient's own language for lifetime PA assessment. ${ }^{11}$ Furthermore, a Bland-Altman analysis indicated neither systematic over- nor underestimation of the recalled PA by the COPD patients, and we found no significant differences in the agreement of the recall of the PA performed 10 years ago between the COPD patients and the SHS. This acceptable accuracy of the long-term recall is consistent with the data of the PA performed more than 20 years ago. We observed no significant difference in the recalled PA between the COPD patients and the active control subjects. As the patients were unlikely to have experienced exercise intolerance associated with COPD at this time $(>40 \mathrm{y})$, the distant-past PA did not appear to be misestimated in COPD. Thus, in spite of a strict prospective validation of the lifetime recalled PA using actimetry recordings, the accuracy of the lifetime PA in the COPD patients appeared acceptable and not systematically biased. This can be explained by the particular care we took in collecting information: we gave them full oral and written explanations, they were asked to prewrite their answers 2 to 5 days before the interview, and the interviews (with an experienced practitioner) lasted almost 45 minutes for both populations.

Last, the difference in the sex ratio (more men in the COPD group) could explain the higher lifetime PA in the COPD patients. However, in a subgroup of 27 SHS and 27 COPD patients wellmatched for age, sex, and had no past rehabilitation, we still found the same PA for the past 15 years and a higher PA from 16 to 40 years ago for the COPD patients compared with SHS (supplemental fig 2).

\section{CONCLUSIONS}

Our COPD patients had normative PA levels more than 20 years ago. However, they reduced their PA at an early age (45 (35-54) y, 10y before SHS) and reached the PA level of SHS 15 years ago. Their PA pattern from this point onward was the same as that of SHS. Interestingly, the PA reduction preceded all clinical signs of disease. This finding challenges the classical paradigm of the COPD spiral of decline and suggests the implication of prior pathologic mechanisms in the PA reduction of COPD patients.

Acknowledgements: We would especially like to thank M. Gerard Piñol, PT, for his technical contribution to this work, and all the team of the pulmonary rehabilitation center "La Solane," Osséja, France.

\section{References}

1. Serres I, Gautier V, Varray A, Prefaut C. Impaired skeletal muscle endurance related to physical inactivity and altered lung function in COPD patients. Chest 1998;113:900-5.

2. Couillard A, Prefaut C. From muscle disuse to myopathy in COPD: potential contribution of oxidative stress. Eur Respir J 2005;26:703-19.

3. Pitta F, Troosters T, Spruit MA, Probst VS, Decramer M, Gosselink R. Characteristics of physical activities in daily life in chronic obstructive pulmonary disease. Am J Respir Crit Care Med 2005;171:972-7.
4. Garcia-Aymerich J, Félez MA, Escarrabill J, et al Physical activity and its determinants in severe chronic obstructive pulmonary disease. Med Sci Sports Exerc 2004;36:1667-73.

5. Wagner PD. Skeletal muscles in chronic obstructive pulmonary disease: deconditioning, or myopathy? Respirology 2006;11: 681-6.

6. Oguma Y, Sesso HD, Paffenbarger RS Jr, Lee IM. Physical activity and all cause mortality in women: a review of the evidence. Br J Sports Med 2002;36:162-72.

7. Vallet G, Varray A, Fontaine JL, Prefaut C. [Value of individualized rehabilitation at the ventilatory threshold level in moderately severe chronic obstructive pulmonary disease] [French]. Rev Mal Respir 1994;11:493-501.

8. Young A. Rehabilitation of patients with pulmonary disease. Ann Acad Med Singapore 1983;12:410-6.

9. Watz H, Waschki B, Meyer T, Magnussen H. Physical activity in patients with COPD. Eur Respir J 2009;33:262-72.

10. Falkner KL, Trevisan M, McCann SE. Reliability of recall of physical activity in the distant past. Am J Epidemiol 1999;150: 195-205.

11. Vuillemin A, Guillemin F, Denis G, Huot J, Jeandel C. A computer-assisted assessment of lifetime physical activity: reliability and validity of the QUANTAP software. Rev Epidemiol Sante Publique 2000;48:157-67.

12. Vuillemin A, Guillemin F, Jouanny P, Denis G, Jeandel C. Differential influence of physical activity on lumbar spine and femoral neck bone mineral density in the elderly population. J Gerontol A Biol Sci Med Sci 2001;56:B248-53.

13. Rabe KF, Hurd S, Anzueto A, et al. Global strategy for the diagnosis, management, and prevention of chronic obstructive pulmonary disease: GOLD executive summary. Am J Respir Crit Care Med 2007;176:532-55.

14. Moullec G, Ninot G, Varray A, Prefaut C. [What are the postrehabilitation options for patients with COPD?] [French]. Rev Mal Respir 2007;24:121-32.

15. Pitta F, Troosters T, Probst VS, Langer D, Decramer M, Gosselink R. Are patients with COPD more active after pulmonary rehabilitation? Chest 2008;134:273-80.

16. Mador MJ, Patel AN, Nadler J. Effects of pulmonary rehabilitation on activity levels in patients with chronic obstructive pulmonary disease. J Cardiopulm Rehabil Prev 2011;31:52-9.

17. Nelson ME, Rejeski WJ, Blair SN, et al. Physical activity and public health in older adults: recommendation from the American College of Sports Medicine and the American Heart Association. Med Sci Sports Exerc 2007;39:1435-45.

18. INSERM. Physical activity: context and and effects on health. 1st ed. Paris: INSERM editions; 2008.

19. Voorrips LE, Ravelli AC, Dongelmans PC, Deurenberg P, Van Staveren WA. A physical activity questionnaire for the elderly. Med Sci Sports Exerc 1991;23:974-9.

20. Steele BG, Holt L, Belza B, Ferris S, Lakshminaryan S, Buchner DM. Quantitating physical activity in COPD using a triaxial accelerometer. Chest 2000;117:1359-67.

21. Hecht A, Ma S, Porszasz J, Casaburi R. Methodology for using long-term accelerometry monitoring to describe daily activity patterns in COPD. COPD 2009;6:121-9.

22. Bland JM, Altman DG. Statistical methods for assessing agreement between two methods of clinical measurement. Lancet 1986; 1:307-10.

23. Bestall JC, Paul EA, Garrod R, Garnham R, Jones PW, Wedzicha JA. Usefulness of the Medical Research Council (MRC) dyspnoea scale as a measure of disability in patients with chronic obstructive pulmonary disease. Thorax 1999;54:581-6.

24. Quanjer PH, Tammeling GJ, Cotes JE, Pedersen OF, Peslin R, Yernault JC. Lung volumes and forced ventilatory flows. Report Working Party Standardization of Lung Function Tests, European 
Community for Steel and Coal. Official Statement of the European Respiratory Society. Eur Respir J Suppl 1993;16:5-40.

25. Bansal V, Hill K, Dolmage TE, Brooks D, Woon LJ, Goldstein RS. Modifying track layout from straight to circular has a modest effect on the 6-min walk distance. Chest 2008;133:1155-60.

26. Troosters T, Gosselink R, Decramer M. Six minute walking distance in healthy elderly subjects. Eur Respir J 1999;14:270-4.

27. Vallet G, Ahmaidi S, Serres I, et al. Comparison of two training programmes in chronic airway limitation patients: standardized versus individualized protocols. Eur Respir J 1997;10:114-22.

28. Delample D, Durand F, Severac A, et al. Implication of xanthine oxidase in muscle oxidative stress in COPD patients. Free Radic Res 2008;42:807-14.

29. Macfarlane DJ, Lee CC, Ho EY, Chan KL, Chan D. Convergent validity of six methods to assess physical activity in daily life. J Appl Physiol 2006;101:1328-34.

30. Andersen LB. Relative risk of mortality in the physically inactive is underestimated because of real changes in exposure level during follow-up. Am J Epidemiol 2004;160:189-95.

31. Fleg JL, Morrell CH, Bos AG, et al Accelerated longitudinal decline of aerobic capacity in healthy older adults. Circulation 2005;112:674-82.

32. Hillsdon MM, Brunner EJ, Guralnik JM, Marmot MG. Prospective study of physical activity and physical function in early old age. Am J Prev Med 2005;28:245-50.

33. Janaudis-Ferreira T, Wadell K, Sundelin G, Lindstrom B. Thigh muscle strength and endurance in patients with COPD compared with healthy controls. Respir Med 2006;100:1451-7.

34. Touvier M, Bertrais S, Charreire H, Vergnaud AC, Hercberg S, Oppert JM. Changes in leisure-time physical activity and sedentary behaviour at retirement: a prospective study in middle-aged French subjects. Int J Behav Nutr Phys Act 2010;7:14.

35. Sherwood NE, Jeffery RW. The behavioral determinants of exercise: implications for physical activity interventions. Annu Rev Nutr 2000;20:21-44.

36. Hill K, Goldstein RS. Limited functional performance in chronic obstructive pulmonary disease: nature, causes and measurement. COPD 2007;43:257-61.
37. Amann M, Regan MS, Kobitary M, et al. Impact of pulmonary system limitations on locomotor muscle fatigue in patients with COPD. Am J Physiol Regul Integr Comp Physiol 2010;299:R314-24.

38. Ofir D, Laveneziana P, Webb KA, Lam YM, O'Donnell DE Mechanisms of dyspnea during cycle exercise in symptomatic patients with GOLD stage I chronic obstructive pulmonary disease. Am J Respir Crit Care Med 2008;177:622-9.

39. Seymour JM, Spruit MA, Hopkinson NS, et al. The prevalence of quadriceps weakness in COPD and the relationship with disease severity. Eur Respir J 2010;36:81-8.

40. Bernaards CM, Twisk JW, Van Mechelen W, Snel J, Kemper HC. A longitudinal study on smoking in relationship to fitness and heart rate response. Med Sci Sports Exerc 2003;35:793800 .

41. Montes de Oca M, Loeb E, Torres SH, De Sanctis J, Hernandez N, Talamo C. Peripheral muscle alterations in non-COPD smokers. Chest 2008;133:13-8.

42. Marciniuk DD, Brooks D, Butcher S, et al. Optimizing pulmonary rehabilitation in chronic obstructive pulmonary disease-practical issues: a Canadian Thoracic Society Clinical Practice Guideline. Can Respir J 2010;17:159-68.

43. Dodd JW, Getov SV, Jones PW. Cognitive function in COPD. Eur Respir J 2010;35:913-22.

44. Chasan-Taber L, Erickson JB, McBride JW, Nasca PC, ChasanTaber S, Freedson PS. Reproducibility of a self-administered lifetime physical activity questionnaire among female college alumnae. Am J Epidemiol 2002;155:282-9.

45. Smith WR, White PD, Buchwald D. A case control study of premorbid and currently reported physical activity levels in chronic fatigue syndrome. BMC Psychiatry 2006;6:53.

\section{Suppliers}

a. Tritrac RT3 Research; Stayhealthy Inc, 724 East Huntington Dr Ste A-D, Monrovia, CA 91016.

b. Sensormedics, 22705 Savi Ranch Parkway, Yorba Linda, CA 92887-4645.

c. Roche OMNI S; Roche Diagnostics, Sandhofer Straße 116, 68305 Mannheim, Germany.

d. Ergoselect 200P; Ergoline, Lindenstrasse 5, 72475 Bitz, Germany. 


\section{SUPPLEMENTARY MATERIALS SUBJECTS AND METHODS}

\section{Participants}

Rehabilitation within the past 5 years was not an exclusion criterion because we assumed that this would not change the lifetime pattern of PA. ${ }^{1-3}$ This statement was confirmed by the lack of any statistical difference neither in the lifetime amount, nor in the pattern of the past 30 years, or in the age of PA reduction between COPD patients that beneficiated of a pulmonary rehabilitation $(\mathrm{R})$ in the past 5 years, and never rehabilitated (NR) COPD patients (see supplemental fig 3):

- Lifetime amount of PA COPD NR: $69962 \pm 44769$ vs COPD R: $77429 \pm 40662 ; P=.32$

- Age of PA reduction: COPD NR: $44.1 \pm 11.4$ vs COPD R: 42.1 $11.9 ; P=.35$

- Lifetime PA pattern during the past 30 years.

\section{Physical activity}

Voorrips questionnaire (modified Baecke's questionnaire) and actimetry. In order to assess the PA level of our sedentaryselected healthy population, we used a PA questionnaire validated ${ }^{4}$ and used in this indication. ${ }^{5}$ The questionnaire scored the past year's household activities, sports activities, and other physically active leisure-time activities and gave an overall PA score. The subjects were asked to describe the type of activity, hours per week spent on it, and period of the year in which the activity was normally performed. All activities were classified according to posture and movement. This questionnaire provides a reliable and valid method for classifying the activity level of older subjects as high, medium, or low. With this method, normal subjects with scores under 9.4 are classified as having low physical activity.

Objective PA level was assessed in 20 COPD patients and 20 SHS who wore a triaxial accelerometer Tritrac RT3 ${ }^{\mathrm{a}}$ Research for 7 consecutive days. ${ }^{6,7}$

Age at dyspnea onset/Age at diagnosis. Breathlessness was systematically recorded using the patient's own dyspnea vocabulary. The severity via the Medical Research Council (MRC) scale ${ }^{8}$ and the age at first occurrence were documented. The intra-observer consistency was assessed in a preliminary study. Twelve patients responded to the questionnaire twice, with a six-month interval, and no significant differences in responses were observed $(P=.44)$. The intra-observer correlation coefficient was excellent: $\mathrm{R}^{2}=0.98(\mathrm{n}=12)$.

All clinical events in the disease (diagnosis, first rehabilitation) were linked to meaningful events in the subject's life (children's birthdays, wedding anniversary, work, etc.).

Exercise testing and muscle function assessment. The 6-minute walking test was performed in a 30-meter corridor as previously described. ${ }^{9}$ The distance walked during the test was compared with reference values. ${ }^{10}$ Patients were asked to walk at their own maximal rate. They were asked to cover as much ground as possible in 6 minutes while walking at a steady rate with no running. Arterial oxygen saturation and heart rate were monitored every minute using a pulse oximeter.

Muscle function assessment. The maximal voluntary contraction and T.lim were assessed with the usual methods of our group. ${ }^{5,11,12}$ Briefly, the maximal voluntary contraction was measured at $90^{\circ}$ on a bench. Three reproducible measurements (within 10\%) of the force of the dominant leg were recorded and the best value was retained as the maximal voluntary contraction. The T.lim was then measured as the time (in s) during which the subjects were able to maintain a contraction at $30 \%$ of maximal voluntary contraction, and at the rate of 10 movements per minute to exhaustion. A reduction in maximal voluntary contraction $>10 \%$ in 1 min was defined as fatigue and validated the test.

\section{References}

1. Moullec G, Ninot G, Varray A, Prefaut C. What are the postrehabilitation options for patients with COPD? Rev Mal Respir 2007;242:121-32.

2. Pitta F, Troosters T, Probst VS, Langer D, Decramer M, Gosselink R. Are patients with COPD more active after pulmonary rehabilitation? Chest 2008;1342:273-80.

3. Mador MJ, Patel AN, Nadler J. Effects of pulmonary rehabilitation on activity levels in patients with chronic obstructive pulmonary disease. J Cardiopulm Rehabil Prev 2011;311:52-9.

4. Voorrips LE, Ravelli AC, Dongelmans PC, Deurenberg P, Van Staveren WA. A physical activity questionnaire for the elderly. Med Sci Sports Exerc 1991;238:974-9.

5. Serres I, Gautier V, Varray A, Prefaut C. Impaired skeletal muscle endurance related to physical inactivity and altered lung function in COPD patients. Chest 1998;1134:900-5.

6. Steele BG, Holt L, Belza B, Ferris S, Lakshminaryan S, Buchner DM. Quantitating physical activity in COPD using a triaxial accelerometer. Chest 2000;1175:1359-67.

7. Hecht A, Ma S, Porszasz J, Casaburi R. Methodology for using long-term accelerometry monitoring to describe daily activity patterns in COPD. Copd 2009;62:121-9.

8. Bestall JC, Paul EA, Garrod R, Garnham R, Jones PW, Wedzicha JA. Usefulness of the Medical Research Council (MRC) dyspnoea scale as a measure of disability in patients with chronic obstructive pulmonary disease. Thorax 1999;547:581-6.

9. Bansal V, Hill K, Dolmage TE, Brooks D, Woon LJ, Goldstein RS. Modifying track layout from straight to circular has a modest effect on the 6-min walk distance. Chest 2008;1335:1155-60.

10. Troosters T, Gosselink R, Decramer M. Six minute walking distance in healthy elderly subjects. Eur Respir J 1999;142:270-4.

11. Koechlin C, Couillard A, Simar D, Cristol JP, Bellet H, Hayot M, Prefaut C. Does oxidative stress alter quadriceps endurance in chronic obstructive pulmonary disease? Am J Respir Crit Care Med 2004;1699:1022-7.

12. Delample D, Durand F, Severac A, Belghith M, Mas E, Michel F, Cristol JP, Hayot M, Prefaut C. Implication of xanthine oxidase in muscle oxidative stress in COPD patients. Free Radic Res 2008:429:807-14. 


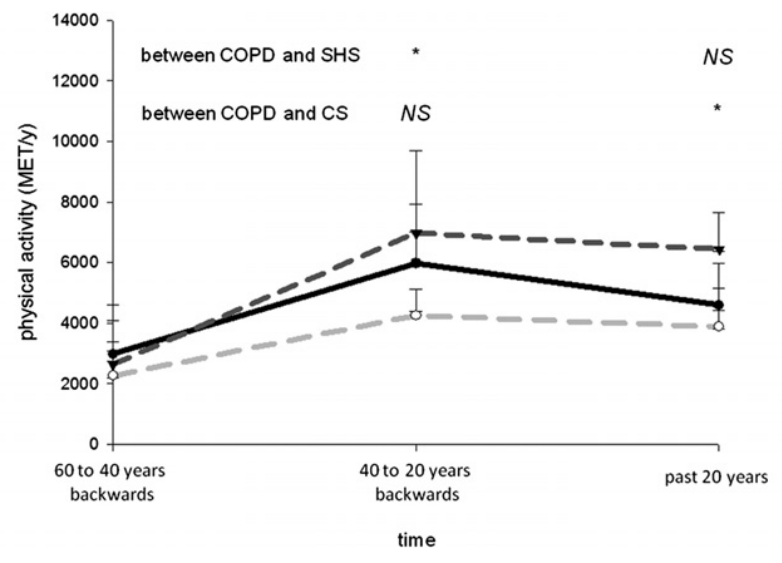

Supplemental Fig 1. Time course for PA for every 20-year period of time backwards, for COPD patients (black), control subjects (gray), and SHS (light gray) in MET. ${ }^{-1}$. Differences between the groups at each period were tested for amount of PA. * $P<.05$. Abbreviation: $\mathrm{MET} / \mathrm{y}$, metablic equivalents per year; NS, nonsignificant.

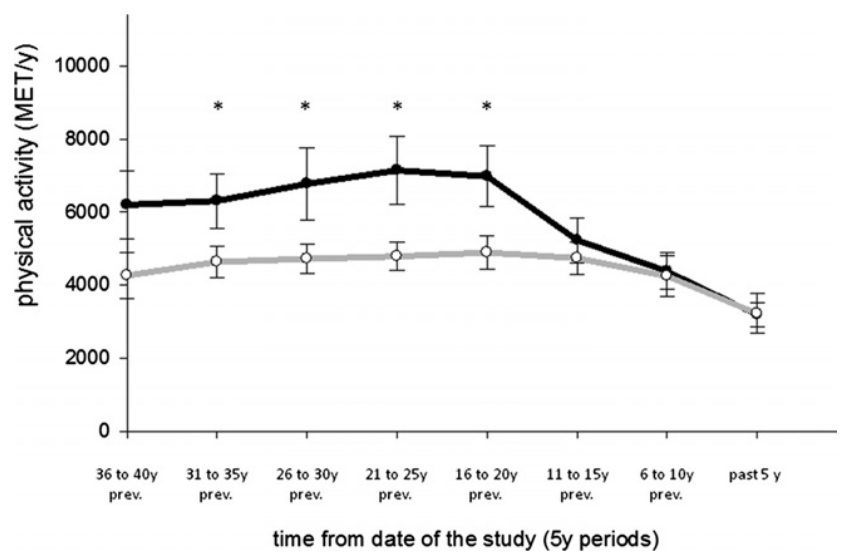

Supplemental Fig 2. Time course of PA from the date of the study for each 5-year period of time in MET. $y^{-1}$ for COPD patients (black) and age-/sex-matched SHS (light gray). Results expressed are in median \pm SEM. Differences between groups at each period were tested for amount of PA. * $P<.05$. Abbreviation: MET/y, metablic equivalents per year.

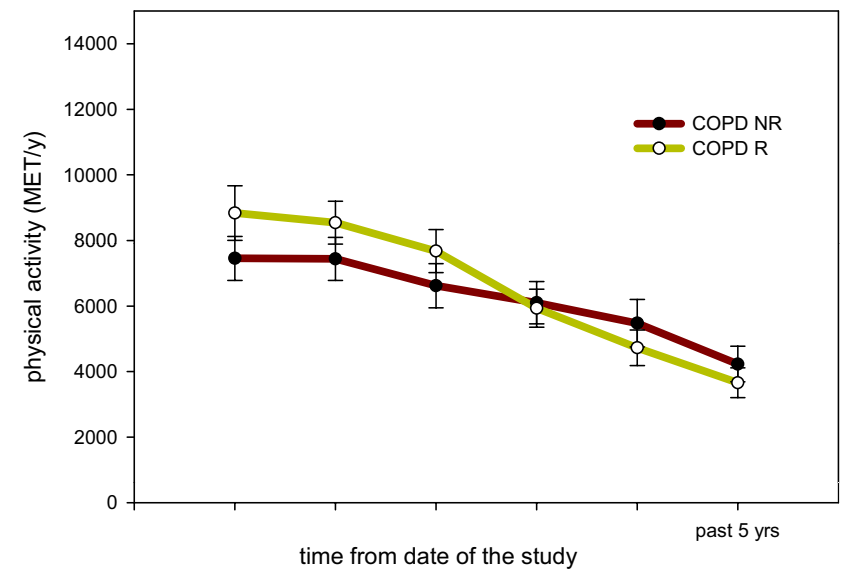

Supplemental Fig 3. Rehabilition within past 5 years. 